\title{
Proposta para construção de um índice local de preços de imóveis a partir dos lançamentos imobiliários de condomínios residenciais*
}

\author{
Sérgio Rozenbaum** \\ T. Diana L. v. A. de Macedo-Soares***
}

SUMÁRIO: 1. Introdução; 2. Revisão da literatura; 3. Conceitos e modelo adotado; 4. Metodologia da pesquisa; 5. Conclusão.

SUMMARY: 1. Introduction; 2. Literature review; 3 . Concept and adopted model; 4. Research methodology; 5 . Conclusion.

Palavras-chave: índice de preços; lançamentos imobiliários; condomínios residenciais; imóveis.

KEY WORDS: price index; new housing; local markets; condos; real estate.

Este artigo propõe um modelo para construção de índices de mercados locais a partir das informações fornecidas nos lançamentos imobiliários residenciais, pois construir um índice de preços nacional para unidades residenciais em um país de dimensões continentais e com uma diversidade cultural e econômica como a do Brasil é muito difícil. Além disso, mesmo nas grandes regiões metropolitanas, faltam informações sobre os preços reais praticados nas transações imobiliárias e sobre as características dos imóveis negociados.

A proposal for a local housing price index based on new residential condos It is very difficult to develop a national housing price index for a country with continental dimensions and the level of cultural and economic

\footnotetext{
* Artigo recebido em set. 2006 e aceito em set. 2007.

** Doutorando em administração e mestre em administração pela Pontifícia Universidade Católica do Rio de Janeiro (IAG/PUC-Rio). Endereço: Av. Ayrton Senna, 3.383, 2o andar - CEP 22775-002, Barra da Tijuca, Rio de Janeiro, RJ, Brasil. E-mail: seroz@globo.com.

*** PhD, professora associada da Pontifícia Universidade Católica do Rio de Janeiro (IAG/PUCRio). Endereço: Rua Marquês de São Vicente, 225 - CEP 22453-900, Gávea, Rio de Janeiro, RJ, Brasil. E-mail: redes@strategy-research.com.
} 
diversity such as Brazil. In addition, even at large metropolitan areas, there is a lack of information regarding the actual price of the real estate transactions and the characteristics of those units. The authors propose a model for developing an index of local markets based on information made available during the release of new residential real estate properties.

\section{Introdução}

Recente estudo nos 18 países-membros da OCDE (Girouard e colaboradores, 2005), sobre comportamento dos preços reais das unidades imobiliárias residenciais nos últimos 35 anos, apresentou conclusões que podem fornecer subsídios à previsão do desempenho do mercado imobiliário residencial no Brasil, nos próximos anos:

- os preços têm subido acima da inflação a partir da metade da década de 1990;

v grande parte dessa alta se deve ao financiamento a longo prazo, com taxas baixas e fixas, valor total financiado, grande disponibilidade e fácil acesso;

- o aumento da demanda por espaços residenciais está diretamente relacionado a crescimento econômico, crescimento demográfico, escassez de terrenos e restrições legais (leis de zoneamento);

v aumento da população com mais de 30 anos, que formam lares, impulsionando mercado.

Todos os países estudados mantêm índices de preços das residências em nível nacional, alguns desde 1968, sem os quais qualquer estudo seria muito difícil.

Com a publicação de índices de preços regionais e nacionais os pesquisadores dispõem de dados representativos de um grande número de observações e podem estudar as causas das variações dos preços. Sem dimensionar essas variações de preços seria improvável propor e testar hipóteses consistentes aos problemas estudados pelos pesquisadores na área do mercado imobiliário.

Tal situação existe no Brasil, caracterizada pela falta de publicação de um índice de preços fundamentado em uma metodologia adequada, que possa captar as variações dos preços dos imóveis residenciais. Existem índices de preços dos custos da construção que já são publicados há muitos anos (ICC da FGV, Sinapi), mas não existem observações regulares das variações dos preços de vendas no mercado imobiliário. 
Os prováveis motivos são:

- dificuldade na classificação das características das unidades imobiliárias, para então se observarem as vendas realizadas;

จ dados sobre preços de imóveis que não são confiáveis antes de 1995 por causa das inflações ocorridas desde 1962;

v falta de informação sobre os preços reais praticados.

Nos lançamentos imobiliários no Brasil, antes do início da construção, incorporadores adotam diversas ações de marketing e oferecem produtos diferenciados, e pelo menos no segmento da classe média alta é muito difícil encontrar dois empreendimentos razoavelmente semelhantes. É usual, portanto, no mercado, comparar os empreendimentos pelo preço do metro quadrado de área privativa da unidade (área interna da unidade delimitada por portas de acesso ao seu exterior) mesmo quando suas características são diferenciadas levando à observação de preços diferentes.

O mercado imobiliário residencial no Brasil tem como característica o longo período de uso por uma mesma família da mesma residência. Assim, devido à pouca mobilidade da população de classe média alta, objeto deste artigo, não há dados suficientes nem registros para uma avaliação de preços com o uso do método de vendas repetidas, que requer observações de vendas realizadas de um mesmo imóvel ao longo do tempo.

Já nos EUA, onde o período de uso de uma mesma residência é mais reduzido, por causa da constante mobilidade, a literatura coloca em evidência o método de vendas repetidas, que é considerado o mais indicado para mensurar as variações de preços em um produto heterogêneo, e tem como um de seus principais questionamentos o fato de não captar o investimento das benfeitorias realizadas no imóvel ao longo do tempo.

Mesmo assim, o método de vendas repetidas é largamente utilizado. Um dos índices que é muito utilizado nos EUA é o CMHPI (conventional mortage home price index). Esse índice é apurado a partir das hipotecas adquiridas em todo o país e publicado pelas empresas, patrocinadas pelo governo dos EUA, Federal Home Loan Mortgage Corporation (Freddie Mac) e Federal National Mortgage Association (Fannie Mae), que compram e securitizam os empréstimos de longo prazo (Stephens et. al., 1995) e são responsáveis pela liquidez do sistema. Outro índice, o HPI (house price index) usa os dados das residências unifamiliares (não são computadas as unidades em condomínios, cooperativas e em desenvolvimentos urbanos) com pelo menos duas hipotecas 
compradas desde 1975. É publicado por um órgão federal, o Office of Federal Housing Enterprise Oversight (Ofheo). Os índices são construídos a partir do método WRS (weighted-repeat sales), uma das variações do método de vendas repetidas (Calhoun, 1996).

A publicação de um índice de preços é um requisito importante para a apuração dos riscos a que as carteiras hipotecárias estão sujeitas. As propriedades que garantem os títulos hipotecários negociados no mercado financeiro podem se desvalorizar e comprometer o sistema, e o órgão regulador deve ser capaz de dispor de índices que reflitam os preços dos imóveis (Calhoun, 1996). O governo brasileiro tem proposto medidas de incentivo à construção civil tais como redução de impostos de insumos, redução da alíquota de imposto de renda, instituição da alienação fiduciária e simplificação tributária para pequenas e médias empresas de construção, que juntamente com a maior oferta de financiamentos imobiliários de longo prazo podem criar condições para uma reação do setor. Para que o mercado imobiliário produza os efeitos desejados será desejável que se desenvolva no Brasil, a exemplo do ocorrido nos EUA, um mercado secundário de hipotecas, derivado e suportado pelas medidas implantadas pelo poder público (Carneiro e Valpassos, 2003:65).

Além da utilidade como moradia, uma unidade imobiliária é também um investimento financeiro, e a construção de um índice de preços passa a ser necessária para a observação de sua volatilidade, para a estimativa dos retornos esperados e para sua avaliação. Assim, os compradores poderão medir o retorno de seus investimentos, e os gerentes poderão estimar seus preços conforme parâmetros valorizados pelo mercado.

O objetivo deste artigo é propor uma metodologia para a construção de um índice de preços local, a partir das informações dos lançamentos imobiliários destinados à classe média alta. É para esse segmento da população que, atualmente, no Brasil, se concentra a maioria dos lançamentos imobiliários.

Ao propor um índice de preço local, precisamos embasar o modelo em outros já existentes na literatura e modificá-lo conforme as particularidades do mercado brasileiro, em estágio de pouco desenvolvimento se comparado aos EUA e à Comunidade Européia. Entre vários modelos estudados, escolhemos o adotado por Laferrère (2003), que define regiões geográficas dentro de uma cidade (Paris, França), baseadas na premissa de que em tais zonas as variações de preços são homogêneas.

Ao modelo de índice proposto, atribuímos a sigla LIR-CMA (lançamento imobiliário residencial - classe média alta). Os autores testaram o modelo em um mercado local (Barra da Tijuca, na cidade do Rio de Janeiro) em fase de expansão acelerada. 
A estrutura do artigo é a seguinte: a seção 2 apresenta uma revisão da literatura pertinente ao tema, a 3 esclarece as definições dos conceitos centrais ao estudo, os objetivos da pesquisa e o modelo adotado. Na seção 4 explicamos a metodologia da pesquisa e apresentamos seus resultados. Na última seção, fazemos as considerações finais.

\section{Revisão da literatura}

Estudos com o uso de modelos hedônicos evidenciaram as principais questões percebidas pelos compradores, que influenciam sua decisão de compra: vizinhança, localização, amenidades, taxas de financiamento (Clapp, 2004; Frew e Jud, 2003; Clapp e Giaccotto, 2002). Outros estudos abordaram características também importantes quando se trata da decisão pela aquisição de imóveis, como: liquidez (Cauley e Pavlov, 2002) e custos de construção (Guirguis, Giannikos e Anderson, 2005; Jud e Winkler, 2002).

Pesquisas sobre a dificuldade de diversificação no segmento imobiliário, os retornos dos investimentos efetuados (Young e Graff, 1995), a sensibilidade dos preços aos movimentos de taxas de juros (Jud e Winkler, 2002) e a percepção do risco financeiro que determina os prêmios de mercado, abordam questões que explicam variações nos preços.

Os pesquisadores que têm tratado das avaliações de imóveis sob aspectos mais particulares tais como a produção e a demanda (Judd e Winkler, 2002), quanto ao método da avaliação (Frew e Jud, 2003; Clapp e Giaccotto, 2002; Macanham, Montevecchi e Pamplona; 2001), pela conveniência do uso de informações geográficas (Wubneh e Shen, 2004; Din, Hoesli e Bender, 2001), da segurança apresentada contra alguns tipos de crimes (Maia, 1998; Buck, Hakim e Spiegel, 1993), da localização do imóvel (Bond, Seiler e Seiler, 2002; Isakson, 2001), da sua depreciação ao longo do tempo (Smith, 2004), da aplicabilidade de índices de preços (Clapp, 2004; Palmquist, 1980), o fizeram com a preocupação em propor modelos de preços.

Estudar as causas das variações de preços dos imóveis residenciais e registrar os preços praticados são os requisitos para a construção de índices de preços representativos em determinado mercado.

\section{Construção de um índice de preço para imóveis residenciais}

O método mais utilizado para a construção de um índice de preços, cujo objetivo é medir a variação dos preços (inflação) nos imóveis residenciais, é 
o de vendas repetidas, a partir do trabalho seminal de Bailey, Muth e Nourse, 1963 (em Wang e Zorn, 1997). Outros pesquisadores consideram esse método indicado para a formação de um índice de preços (Case e Shiller, 1989; Shiller, 1991).

A principal qualidade do método de vendas repetidas é usar as diversas transações ocorridas com um mesmo imóvel, ao longo do tempo, para medir variações dos preços. Ele apresenta como principal vantagem sobre o método de regressões hedônicas, o fato de que as observações de preços são feitas nas transações com o mesmo imóvel. Já na regressão com as variáveis dependentes hedônicas, onde são levadas em consideração as características dos imóveis e suas relações com os preços, essas características devem ser muito bem especificadas, para uma correta aplicação do método (Wang e Zorn, 1997). Por exemplo, entre as 20 características mais utilizadas dos modelos hedônicos estão as seguintes: distância de um centro de comércio, se a casa tem lareira, ar condicionado, piscina (Sirmans, Macpherson e Zietz, 2005). Essa portanto é a dificuldade quando o estudo é realizado em nível nacional, pois seria como tratar desses atributos em regiões diferentes, já que uma lareira valoriza o imóvel situado em regiões de clima frio, mas não faz o mesmo efeito em regiões de temperatura mais alta. Entre as objeções ao método de vendas repetidas, o desperdício de dados é a mais freqüente (Wang e Zorn, 1997) e os custos de renovação e reforma das propriedades que, quando é um valor significativo mas não informado, pode distorcer a comparação dos preços (Stephens et al., 1995). A construção de um índice de preços nacional, onde os atributos que os compradores valorizam nas unidades residenciais mudam a cada região só é possível quando os preços são observados nas transações ocorridas num mesmo imóvel.

A necessidade da construção de índices de preços imobiliários, embora para propriedades industriais, foi levantada em Hoag (1980) para que se pudessem medir retornos dos investimentos e seu gerenciamento. Palmquist (1980) apontou como melhores técnicas de construção de índices aquelas com o uso do método das vendas repetidas e modelos hedônicos. Propôs em seu artigo um método alternativo, para que fosse possível distinguir entre variações de preços, depreciação e diferenças nas características.

Knight, Dombrow e Sirmans (1995) concluíram que a disputa entre escolher modelos de vendas repetidas, hedônicos ou modelos híbridos está mal colocada e o fundamental é determinar se os parâmetros têm estabilidade durante o período do índice ou podem variar.

Calhoun (1996) adotava o método WRS, método das vendas repetidas, atribuindo pesos, por causa das observações ao longo do tempo apresentarem 
variações, devido à depreciação e às mudanças demográficas e socioeconômicas das localidades.

Clapp e Giaccotto (1998) concluíram que o modelo HRM (hedonic repeatsales measure) era virtualmente idêntico ao método de vendas repetidas desde que se especificassem corretamente as características hedônicas mais relevantes. Concluíram que isso pode ser feito (a correta especificação) com a verificação de mudanças ao longo do tempo, em relação às novas construções (por exemplo, as novas construções têm mais banheiros). O HRM (um modelo híbrido) ao incorporar vendas repetidas, reduziu o número dos atributos associados aos modelos hedônicos.

Benson e colaboradores (1998) estabeleceram por meio do uso de um modelo hedônico o impacto no preço quando o imóvel tem uma vista, conforme sua qualidade e sua distância do imóvel.

Englund, Quigley e Redfearn (1999) argüiram que embora a compra da casa própria seja provavelmente o maior investimento das famílias, e elas fazem seguros contra perdas devido a desastres naturais (incêndio, enchentes etc.), jamais se preocupam em proteger contra a perda de valor. Pode haver várias barreiras à existência de produtos que possam proteger as famílias contra perda de seu patrimônio, mas o ponto de partida teria de ser a acurada medição dos níveis de preços e suas volatilidades, ou seja, um índice que pudesse ser adotado pelas empresas seguradoras. As barreiras à construção desse índice são a falta de freqüência nas vendas e a heterogeneidade nas características das casas. O artigo usou índices construídos sobre a mesma base de dados (WRS e híbrido), e as vendas ocorreram em três das maiores regiões metropolitanas da Suécia, entre 1981 e 1993, onde em 168.920 registros, 45.997 eram de vendas repetidas. Consideraram que o amplo uso do WRS pode levar a um quadro inadequado dos movimentos dos preços.

Conniffe e Duffy (1999) estudaram algumas das metodologias dos índices de preços e discutiram o Esri index, índice adotado na Irlanda e publicado desde 1996. Na Irlanda não há uma instituição que promova a compra e securitização das hipotecas, logo não se publica nenhum índice baseado em vendas repetidas. $\mathrm{O}$ artigo compara índices baseados na média, mediana, modelo hedônico e modelo hedônico restrito. Recomendaram pesquisar como se poderia identificar vendas repetidas, já que esses modelos prevalecem na literatura.

Clapp e Giaccotto (2002) analisaram em uma mesma base de dados (Dade County, Florida, 1971-1997) o uso dos modelos de vendas repetidas e hedônicas para previsão de preços futuros e suas variações, chegando à conclusão de que um modelo baseado no método hedônico é superior.

Malpezzi (2002) em uma revisão bibliográfica sobre modelos hedônicos destacou, como fatores importantes que afetam os preços, distância ao centro 
de comércio, amenidades e a qualidade da região. Evidenciou que o modelo hedônico tem como primeira e mais importante finalidade fazer melhorias na qualidade dos índices de preços de unidades residenciais.

Hwang e Quigley (2004) destacaram as limitações do método mais usado nos EUA, o método das vendas repetidas: dificuldades em medir as benfeitorias realizadas, que as casas com mais vendas repetidas podem não ser uma amostra aleatória da população das casas ocupadas por seus donos, ao aplicar o modelo assumem que os preços dos imóveis sejam do tipo aleatório (random walk) e que pares de vendas forneçam as informações necessárias. Propuseram um modelo híbrido que permitia análise conjunta de mudanças na seleção e na qualidade.

Bourassa, Hoesli e Sun (2005) apresentaram um método para a construção de índice de preços que é usado desde 1982 na Nova Zelândia, o Spar (sale price appraisal ratio) e o compararam com índices construídos pelo método de vendas repetidas e por um modelo hedônico, com base nas mesmas transações. O Spar é um índice aritmético (vendas repetidas) construído a partir da relação entre uma venda no mercado aberto sobre a avaliação oficial da propriedade. Concluíram que o Spar produz resultados parecidos com o modelo hedônico, é fácil de construir e não necessita de base de dados detalhada, quanto aos atributos das propriedades.

\section{Construção de um índice de preço local para imóveis residenciais}

Mark e Goldberg (1984) acreditam que os melhores critérios para a escolha de um índice são:

v uma fundamentação consistente;

v ser de simples administração;

จ ser razoavelmente estável.

O estudo que foi feito com a construção de 11 diferentes índices para preços, na região de Vancouver, no Canadá, entre 1957 e 1979, recomendou cuidados especiais com as áreas geográficas cobertas pelos índices e recomendou utilização de três índices, sendo um baseado em modelo hedônico.

Case e Quigley (1991) propuseram um modelo híbrido a partir de modelos de vendas repetidas, com e sem modificações, e de vendas simples. O modelo apresentou vantagens quando aplicado em uma mesma vizinhança (no Havaí, EUA). A região em Honolulu, denominada Kahala, onde se aplicou 
o modelo, compreendia 1.100 residências delimitadas geograficamente por uma praia, um campo de golfe e uma auto-estrada.

Case e Szymanosky (1995) em estudo na área de San Francisco, Califórnia, com dados das 49.266 transações ocorridas entre 1977 e 1984, observaram que 18.562 eram de vendas repetidas. Entre os modelos propostos no artigo - o hedônico, o do método de vendas repetidas com pesos (WRS weighted-repeat sale) e um modelo híbrido - concluíram que o último apresentou mais precisão.

Meese e Wallace (1997), em estudo com residências unifamiliares na Califórnia, EUA, num período de 18 anos (1970-1988) com pequena abrangência geográfica (limitava-se aos municípios de Oakland e Freemont), encontraram problemas para validar o método de vendas repetidas.

Schwann (1998) estudou mercados regionais (vizinhanças) de poucas transações, usando séries temporais cuja desvantagem é o alisamento, mas que traz a precisão como vantagem. A importância do estudo ao focar nos pequenos mercados é poder estabelecer quando ele é um submercado (isto é, de comportamento diferente do mercado como um todo). Ele propôs o uso da equação hedônica, com seis atributos: idade, área do lote, área privativa, número de quartos, número de banheiros, número de lareiras. Baseou-se em dados (entre 1979 e 1992) de um bairro, Mount Pleasant, da cidade de Vancouver, no Canadá, que representava apenas $2 \%$ das transações da cidade. Estimou as regressões hedônicas do local e do resto da cidade, e usou o teste estatístico $\mathrm{F}$ test para testar os coeficientes das duas áreas estudadas. A hipótese nula foi rejeitada (de que os mercados se comportam igualmente). Concluiu então que com um modelo hedônico restrito e uma abordagem por série temporal, é possível construir índices com credibilidade.

Tiwari e Hasegawa (2000) estudaram um dos mercados mais caóticos do mundo, Mumbai (Bombaim), segunda cidade da Índia, no período de 19891995, quando houve um grande movimento de alta nos preços. Na questão dos dados, os autores reportam problemas em determinar o valor real das transações com as unidades, já que parte do montante é pago em espécie e não registrada na escritura, sobre a qual as empresas hipotecárias emprestam e de onde os autores tiram seus dados. Para determinação do preço final com base na hipoteca os autores recorreram a corretores em cada zona da cidade. Não havia índice de preços em Mumbai, e os autores construíram dois modelos de uma equação hedônica, explicit-time-variable (ver Clapp e Giaccotto, 1991), onde o tempo é uma variável (dummy) independente, e um modelo strictly cross-sectional, onde preços são estimados em uma regressão para cada período de tempo. Concluíram pela recomendação do uso do índice Fisher e do modelo hedônico cross-sectional. 
Leishman e Watkins (2002) afirmaram que os métodos de construção de índices no Reino Unido eram inferiores aos utilizados na Comunidade Européia, Austrália e EUA e que a solução seria um sistema de índices locais (para as maiores cidades). Construíram pela primeira vez um índice baseado no método de vendas repetidas com resultados variando conforme a cidade. Os dados existentes para a construção dos índices foram considerados satisfatórios para a Escócia, mas com problemas para a Inglaterra e Gales.

Alencar e Lazzarotto (2002), em um dos raros artigos brasileiros sobre índices de preços residenciais, com poucas observações em um mesmo ano (dezembro, abril e julho), pesquisaram a construção de um índice pelo método hedônico já que consideraram difícil encontrar vendas repetidas. Limitaram sua pesquisa a um pequeno bairro da cidade de São Paulo (Moema) com grande atividade de lançamentos imobiliários e atribuíram pesos a algumas características dos imóveis. Os atributos com pesos, escolhidos pelos autores, foram: padrão da área de lazer, acabamento da construção, localização, poluição sonora (no caso, aviões, devido à proximidade do aeroporto de Congonhas).

Laferrère (2003) relata o papel desempenhado pelos notários franceses na criação dos índices de preços na França, a partir da obrigação de certificação das vendas de imóveis e da comunicação regular dessas informações, já que os notários são nomeados funcionários públicos. O estudo destaca que o modelo hedônico deve ser aplicado em locais onde o preço (por unidade de área) não seja muito diferente e que se movam da mesma forma ao longo do tempo. As vizinhanças que determinam cada zona são definidas por especialistas locais e, por exemplo, em Paris para índices de preços de apartamentos, uma zona pode ser um bairro (arrondissement), um grupamento deles ou parte de um grande. Os resultados de regressões cross-section apresentam poder de explicação, considerados bons, entre 0,25 e 0,40 para entre mil e 3 mil observações e em torno de 20 variáveis.

Chau e colaboradores (2005) estudaram o mercado de imóveis residenciais em Hong Kong, e apontam como grandes dificuldades para a construção de um índice: heterogeneidade, depreciação ou renovação das unidades, falta de dados confiáveis. Foi proposto em seu artigo um índice baseado no método de vendas repetidas, já que naquela cidade os registros dos dados das transações são obrigatórios e disponíveis e os imóveis têm poucas características diferenciadas, e então o compararam com outros quatro índices existentes, encontrando tendências semelhantes.

Mesmo largamente adotado, o método de vendas repetidas e suas variações (com pesos e modelos híbridos) não são uma unanimidade na literatura, conforme o quadro a seguir. 
No Brasil, além da baixa mobilidade, os dados sobre preços de imóveis não são confiáveis antes de 1995 por causa da inflação e da falta de informação correta sobre os preços praticados. Mesmo assim os dados dos últimos anos (1995-2006) no Brasil não permitem o uso do método das vendas repetidas (onde teriam de ser consideradas as vendas de um mesmo imóvel ao longo do tempo e sem registro de modificações físicas).

Não existe no Brasil um órgão público que publique um índice de preços de venda de unidades imobiliárias. Cada prefeitura das grandes regiões metropolitanas arbitra uma planta de valores para a cobrança de impostos sobre a propriedade imobiliária, com critérios de diferenciação tais como localização, idade do imóvel, valor de mercado. Os tabeliães (notários) apenas informam dados de preço e identidade das transações efetivadas, diretamente à Receita Federal.

A partir dessas considerações, adotamos para este artigo construir um índice de preços a partir de um modelo hedônico.

\begin{tabular}{|c|c|c|}
\hline \multicolumn{3}{|c|}{ Estudos ordenados por método } \\
\hline Autor(es) & Método & Contribuições \\
\hline $\begin{array}{l}\text { Sirmans, Macpherson } \\
\text { e Zietz (2005) }\end{array}$ & Modelo hedônico & Pesquisa das características mais utilizadas \\
\hline Laferrère (2003) & Modelo hedônico & Uso em zonas com construções semelhantes \\
\hline Malpezzi (2002) & Modelo hedônico & $\begin{array}{l}\text { Finalidade dos modelos hedônicos é melhorar a qualidade } \\
\text { dos índices }\end{array}$ \\
\hline $\begin{array}{l}\text { Alencar e Lazzarotto } \\
\text { (2002) }\end{array}$ & Modelo hedônico & $\begin{array}{l}\text { Índice de bairro, com atribuição de pesos pelos autores, } \\
\text { conforme julgamento }\end{array}$ \\
\hline $\begin{array}{l}\text { Tiwari e Hasegawa } \\
\text { (2002) }\end{array}$ & Modelo hedônico & Indicaram o uso de um índice do tipo Fisher \\
\hline Wang e Zorn (1997) & Modelo hedônico & $\begin{array}{l}\text { Características das unidades devem ser muito bem } \\
\text { especificadas }\end{array}$ \\
\hline $\begin{array}{l}\text { Benson e colaboradores } \\
\text { (1998) }\end{array}$ & Modelo hedônico & Impacto da vista sobre o preço do imóvel \\
\hline Hwang e Quigley (2004) & Vendas repetidas & $\begin{array}{l}\text { Destacaram as limitações desse método e propuseram um } \\
\text { modelo híbrido }\end{array}$ \\
\hline $\begin{array}{l}\text { Chau e colaboradores } \\
(2005)\end{array}$ & Vendas repetidas & $\begin{array}{l}\text { Heterogeneidade, depreciação e falta de dados confiáveis } \\
\text { são as dificuldades na construção de índices }\end{array}$ \\
\hline Wang e Zorn (1999) & Vendas repetidas & Alerta para o desperdício de dados \\
\hline
\end{tabular}




\begin{tabular}{|c|c|c|}
\hline Autor(es) & Método & Contribuições \\
\hline $\begin{array}{l}\text { Stephens e } \\
\text { colaboradores (1995) }\end{array}$ & Vendas repetidas & $\begin{array}{l}\text { Obras de renovação e reformas, quando não informadas, } \\
\text { distorcem }\end{array}$ \\
\hline Calhoun (1996) & $\begin{array}{l}\text { Vendas repetidas } \\
\text { com pesos (WRS) }\end{array}$ & $\begin{array}{l}\text { Afirmou ser necessário usar o WRS por causa da demografia, } \\
\text { depreciação e mudanças socioeconômicas da região }\end{array}$ \\
\hline $\begin{array}{l}\text { Englund, Quigley e } \\
\text { Redfearn (1999) }\end{array}$ & $\begin{array}{l}\text { Vendas repetidas } \\
\text { com pesos (WRS) }\end{array}$ & $\begin{array}{l}\text { Colocou a necessidade da construção de índices. } \\
\text { Detectaram falhas no WRS }\end{array}$ \\
\hline $\begin{array}{l}\text { Clapp e Giaccotto } \\
\text { (1998) }\end{array}$ & Híbrido & Redução do número de atributos associados (HRM) \\
\hline $\begin{array}{l}\text { Case e Szymanoski } \\
\text { (1995) }\end{array}$ & Híbrido & $\begin{array}{l}\text { Vantagens quando comparado a um hedônico e a outro de } \\
\text { vendas repetidas com pesos }\end{array}$ \\
\hline Case e Quigley (1991) & Híbrido & Vantagens quando aplicado em uma mesma vizinhança \\
\hline $\begin{array}{l}\text { Bourassa, Hoesli e } \\
\text { Sun (2005) }\end{array}$ & Comparações & $\begin{array}{l}0 \text { índice aritmético (Spar) com modelos de vendas } \\
\text { repetidas e modelos hedônicos, com resultados parecidos }\end{array}$ \\
\hline Clapp e Giaccotto (2002) & Comparações & $\begin{array}{l}\text { Superioridade do modelo hedônico para previsão de preços } \\
\text { futuros }\end{array}$ \\
\hline Conniffe e Duffy (1999) & Comparações & Média, mediana, modelo hedônico (geral e restrito) \\
\hline $\begin{array}{l}\text { Knight, Dombrow e } \\
\text { Sirmans (1995) }\end{array}$ & Comparações & Valor atribuído à qualidade dos parâmetros adotados \\
\hline Mark e Goldberg (1984) & Critérios & Consistente, administração simples, estabilidade \\
\hline Meese e Wallace (1997) & Vendas repetidas & Dificuldade de validação em uma região pequena \\
\hline Schwann (1998) & Séries temporais & Estudo em mercados regionais de poucas transações \\
\hline $\begin{array}{l}\text { Leishman e Watkins } \\
\text { (2002) }\end{array}$ & Vendas repetidas & Introdução do método no Reino Unido \\
\hline Hoag (1980) & Seminal & Construção de índices, para propriedades industriais \\
\hline Palmquist (1980) & Seminal & $\begin{array}{l}\text { Propôs método alternativo aos modelos hedônicos e de } \\
\text { vendas repetidas }\end{array}$ \\
\hline
\end{tabular}

\section{Conceitos e modelo adotado}

\section{Lançamentos imobiliários no mercado imobiliário residencial}

Consideramos mercado imobiliário residencial, a produção e comercialização de unidades residenciais para fins de moradia ou investimento; e população de classe média alta aquela que dispõe para renda domiciliar uma quantia superior a 20 salários mínimos (atualmente $\mathrm{R} \$ 7.000$ mensais). Nessa faixa de renda, na região Sudeste do Brasil, não há déficit habitacional (Gonçalves, 1998), supondo, portanto, que as variações de preço não foram afetadas por 
alguma demanda reprimida. O preço justo é aquele que atende aos interesses do empreendedor e do comprador simultaneamente. O empreendedor deve ter satisfeitas suas expectativas de taxa de retorno e velocidade de vendas e o comprador atendidas suas expectativas das utilidades do imóvel como investimento e moradia.

Para o empreendedor, o lançamento imobiliário é um projeto de investimento e como tal tem de produzir uma taxa de retorno, para o capital próprio investido, acima da taxa livre de risco adicionada a um prêmio de risco do mercado imobiliário. $\mathrm{O}$ custo de produção passa a ser, então, um importante fator que regulará a oferta imobiliária. Já uma maior demanda por unidades pelo mercado pode inflacionar o preço das unidades já que os empreendedores subirão os preços até o nível em que for possível não comprometer a velocidade de vendas.

Poucos compradores dispõem de poupança suficiente para uma aquisição imobiliária sem um financiamento de longo prazo. Nessas circunstâncias, a disponibilidade de crédito e taxas de juros adequadas são fatores decisivos na liquidez do mercado imobiliário, respondendo por variações dos preços.

As ações de marketing dos incorporadores, por ocasião dos lançamentos antes do início da construção, são voltadas para evidenciar atributos das unidades e promover um volume de vendas que permita o menor investimento de capital próprio possível, considerado de alto custo. A velocidade de vendas pode, então, ser regulada por variações nos preços conforme a procura, já que a rentabilidade do empreendimento depende do fluxo de recursos.

No Brasil, o acesso ao financiamento imobiliário de longo prazo é restrito, a retomada de imóveis de compradores inadimplentes é demorada e depende de longa ação judicial. Não há índices de preços de imóveis e o mercado de hipotecas é incipiente. As taxas de financiamento são formadas a partir das taxas pagas pelo governo federal, atualmente uma das mais altas taxas reais de juros vigentes no mundo.

Nessas condições uma metodologia para construção de um índice de preços de venda, mesmo a partir de modelos hedônicos, pode proporcionar uma ferramenta de avaliação de preços e seus retornos.

\section{Características que influenciam o preço de um imóvel residencial}

No caso de imóveis residenciais, os potenciais compradores são influenciados por motivos tais como a necessidade de mais espaço, uma localização mais conveniente, por atributos hedônicos (por exemplo, áreas de lazer, vagas para 
automóveis, aposentos mais espaçosos, uma construção mais recente), por uma maior capacidade de comprometimento de renda familiar, pela existência de uma poupança prévia e, sobretudo, pela disponibilidade no mercado de ofertas que atendam a essas necessidades em um nível aceitável.

Sirmans, Macpherson e Zietz (2005) destacam que entre as 20 mais freqüentes características que aparecem nos estudos que avaliam preços de imóveis, estão: área privativa, número de quartos, localização, amenidades, idade do imóvel.

\section{Barreiras para a construção de um índice no Brasil}

A construção de um índice de preços para apartamentos em fase de lançamento imobiliário, objetivo deste artigo, encontra os seguintes problemas:

v a alta inflação existente no período 1962-1995 praticamente inviabilizou a utilização dos dados;

existência de transações que não registram a realidade dos preços, para evitar a taxação;

จ as vendas que são registradas nas prefeituras para pagamento do imposto de transmissão contêm apenas a metragem, endereço e preço. No caso dos lançamentos imobiliários nem há esse registro, já que são lavradas escrituras de promessa de compra e venda, sem exigência de pagamento antecipado do imposto, ou instrumentos particulares;

จ no período 1995-2006 provavelmente se encontrariam poucas vendas repetidas, em relação às vendas totais.

Assim, para atender aos objetivos do artigo, o único índice de preços que pode ser construído é o que utiliza o modelo hedônico.

\section{Modelo adotado}

Um modelo hedônico para construção de índices locais de preços de unidades residenciais com base em apenas lançamentos imobiliários (antes do início da construção), como proposto pelos autores, é inédito. No Brasil, os compradores acreditam que comprar em lançamentos antes do início da construção é sempre a melhor prática. Isso provavelmente se deve à inflação de 1962 a 
1995, quando os investimentos em imóveis eram usados como proteção contra a desvalorização da moeda. Mas, após 1999, a política de altas taxas de juros reais desvalorizou os imóveis, se comparados aos rendimentos da renda fixa, e não permitiu uma oferta de financiamentos em longo prazo.

As vantagens percebidas para a construção de um índice local, baseado apenas nos preços dos lançamentos imobiliários, antes do início da construção, são:

V os preços praticados são reais e estão disponíveis;

v as características das unidades são bem especificadas, e os empreendimentos são apresentados em detalhes. O Código do Consumidor no Brasil é uma das leis mais respeitadas e, portanto, não se questiona o cumprimento de tudo que é proposto em um lançamento imobiliário;

$\checkmark$ ao usar apenas unidades antes do início da construção, ficam excluídas as possibilidades de tendências geradas a partir de modificações e reformas efetuadas ao longo do tempo;

- como não existe a característica da idade para preços de lançamentos imobiliários, uma das preocupações mais presentes da literatura sobre variação de preços dos imóveis (heterocedasticidade, ver Goodman e Thibodeau, 1995 e 1997) não é discutida neste artigo;

$\checkmark$ um índice nessas condições pode servir de instrumento de avaliação para as demais unidades já construídas, por algum método de depreciação.

O objetivo principal deste artigo é a construção de um índice de preços de lançamentos imobiliários residenciais destinados à classe média alta (LIRCMA) a partir dos preços praticados nos lançamentos imobiliários antes do início da construção.

Seleção de variáveis para a construção de índices de imóveis residenciais

Para o índice, foi utilizado o modelo hedônico, onde as principais características adotadas foram:

$\checkmark$ área privativa;

- localização em relação à avenida das Américas (dummy, lado do mar =1);

v distância ao acesso à Zona Sul, à praia e ao centro de comércio (Barrashopping). 
Essas características, principalmente localização e acessos, estudadas em Sirmans e colaboradores (2005), são algumas das mais percebidas pelos compradores. Observamos, por experiência própria, que também nos lançamentos para a classe média alta no Rio de Janeiro, elas são as mais valorizadas.

\section{Metodologia da pesquisa}

Usamos a base de dados da pesquisa Ademi-RJ, considerando que os preços informados foram os preços praticados. Quando as empresas incorporadoras publicam seus preços em jornais, na internet e em outras mídias, ou no estande de vendas, o preço é apresentado em forma de uma tabela para cada unidade, com diferenças conforme a posição relativa. Os preços da base de dados da Ademi-RJ são informados via internet pelos associados (empresas incorporadoras e construtoras do mercado imobiliário) e correspondem à média dos preços do empreendimento por tipo de unidade (número de quartos e apartamento tipo ou cobertura).

Os empreendimentos foram selecionados por sua localização na Barra da Tijuca ao longo da avenida das Américas, principal via da região. Não foram considerados os empreendimentos situados na orla marítima, pois isso iria distorcer a média dos preços em razão do alto impacto da vista para o mar, conforme Benson e colaboradores (1998). Uma vez excluídos os empreendimentos da orla, consideramos o restante dos empreendimentos em duas categorias (em relação à avenida das Américas), aqueles do lado do mar com uma variável (dummy lado mar) de valor um e os outros do lado contrário com valor zero. Os empreendimentos tipo apart-hotel não foram considerados devido à sua característica de investimento imobiliário. Também não foram consideradas as coberturas, cuja escassez (poucas por empreendimento) pode distorcer os preços médios. Os empreendimentos situados na avenida Salvador Allende, avenida Ayrton Senna (Vila Pan-Americana) e da avenida Abelardo Bueno são considerados pelos compradores localizados no bairro de Jacarepaguá e por isso foram descartados.

Os empreendimentos, da base de dados, lançados na área da Barra da Tijuca, no Rio de Janeiro, entre 2002 e 2005, apresentam espaços e equipamentos semelhantes e, portanto, não são observadas características de área de lazer, piscina, quadra de esportes, que trariam diferenças nos preços.

Para representar as distâncias de cada empreendimento ao acesso à Zona Sul, à praia e ao Barrashopping, foi calculada a média geométrica, cujos valores foram obtidos no Google Earth (software baseado em fotos de satélite) pela distância percorrida de automóvel em vias principais até o empreendi- 
mento. Adotamos como referência, para a data de lançamento, variáveis do tipo dummy.

Não foram considerados empreendimentos com menos de 30 unidades, personalizados e de um custo mais alto.

Não estão na pesquisa todos os lançamentos da Barra da Tijuca, pois na base de dados da Ademi-RJ só constam as características dos empreendimentos das empresas associadas e que contribuem com a pesquisa.

\section{Resultados}

Para o tratamento dos dados foi usado o programa estatístico SPSS 13.0, cujos resultados foram:

$\checkmark \mathrm{R}=0,995 ; \mathrm{R}^{2}=0,989 ; \mathrm{R}^{2}$ ajustado $=0,953 ;$

$\checkmark$ Durbin-Watson $=2,182$;

v teste $\mathrm{F}=27,249(\operatorname{sig} 0,000)$;

V VIF com valores entre 1,498 e 4,433.

O modelo de regressão foi proposto com poucas variáveis independentes já que, por uma questão de mercado, os empreendimentos são muito parecidos em suas características de amenidades, número de quartos e meio ambiente. Para diferenciá-los bastam os atributos utilizados: o lado do mar, a área privativa, distância ao centro de comércio, até a praia e ao acesso à Zona Sul da cidade (túnel).

Em pesquisas futuras seria desejável confirmar nossas percepções quanto a outras características dos empreendimentos, não incluídas aqui, e que também podem explicar a variação dos preços: valor da taxa condominial e valor da locação de imóvel similar como indicador da oportunidade de compra.

\section{Índice de preços para a Barra da Tijuca, Rio de Janeiro}

A equação de regressão, assumindo que represente uma relação verdadeira entre a variável dependente (logPreço) e as variáveis independentes pelos resultados obtidos, pode ser escrita assim:

$\log$ Preço $=3,076+1,183 \log$ Area - 0,02 logPSAgeom + 0,064LadoMar + data (mês:ano), onde data é o coeficiente da variável dicotômica que representa o mês de lançamento naquele ano. 
Tabela 1

Resultados da equação de regressão (logPreço)

\begin{tabular}{|c|c|c|c|c|c|c|}
\hline logArea & logPSAgeom & LadoMar & coef. Data & logPreço & Lançamento & Empreendimentos \\
\hline 1,95 & 0,41 & 1 & $-0,012$ & 5,42 & $1 / 3 / 2002$ & Paradiso All Soltes \\
\hline 2,22 & 0,62 & 0 & $-0,007$ & 5,69 & $1 / 5 / 2002$ & Península Green I \\
\hline 2,23 & 0,62 & 0 & $-0,018$ & 5,68 & $1 / 6 / 2002$ & Península Paradiso \\
\hline 1,81 & 0,29 & 1 & $-0,021$ & 5,26 & $1 / 8 / 2002$ & Via Barra \\
\hline 2,26 & 0,48 & 1 & $-0,021$ & 5,78 & 20/8/2002 & Pedra de Itaúna (Reserva de Itaúna) \\
\hline 2,13 & 0,66 & 1 & $-0,059$ & 5,59 & $26 / 11 / 2002$ & Américas Park (Ed. Sun Shine) \\
\hline 2,05 & 0,62 & 0 & 0,076 & 5,56 & $1 / 12 / 2002$ & Peninsula Green II \\
\hline 2,09 & 0,66 & 1 & 0,022 & 5,62 & 19/6/2003 & Américas Park (Ed.Sun View) \\
\hline 2,20 & 0,62 & 0 & $-0,004$ & 5,66 & $1 / 8 / 2003$ & Residencial Monet Peninsula \\
\hline 2,01 & 0,83 & 0 & 0,027 & 5,47 & 30/9/2003 & Blue (Blue One) \\
\hline 2,00 & 0,66 & 1 & 0,052 & 5,54 & $1 / 11 / 2003$ & Américas Park (Ed. Sun Deck) \\
\hline 2,36 & 0,66 & 1 & 0,052 & 5,97 & $1 / 11 / 2003$ & Américas Park (Ed. Sun Prime) \\
\hline 2,10 & 0,62 & 0 & 0,052 & 5,60 & $1 / 11 / 2003$ & Excellence — Península \\
\hline 2,09 . & 0,42 & 0 & 0,052 & 5,59 & $1 / 11 / 2003$ & Le Parc - 1a Fase \\
\hline 2,09 & 0,42 & 0 & 0,057 & 5,60 & $1 / 12 / 2003$ & Le Parc - 2 - Fase \\
\hline 2,04 & 0,42 & 0 & 0,114 & 5,60 & $1 / 2 / 2004$ & Le Parc — 3a Fase \\
\hline 1,86 & 0,62 & 0 & 0,114 & 5,38 & $17 / 2 / 2004$ & Via Bella Península \\
\hline 2,03 & 0,42 & 0 & 0,102 & 5,58 & $1 / 3 / 2004$ & Le Parc — 4a Fase \\
\hline 1,93 & 0,62 & 0 & 0,101 & 5,45 & $1 / 5 / 2004$ & Mandarin Península \\
\hline 2,01 & 0,41 & 1 & 0,019 & 5,53 & $1 / 6 / 2004$ & La Place Residence Service \\
\hline 2,11 & 0,72 & 0 & 0,073 & 5,63 & 27/9/2004 & Blue Vision-Ed. Icon \\
\hline 1,92 & 0,83 & 0 & 0,129 & 5,46 & $1 / 11 / 2004$ & Blue Vision-Ed. Hype \\
\hline 2,25 & 0,66 & 1 & 0,082 & 5,87 & $1 / 3 / 2005$ & Américas Park (Ed. Sun Special) \\
\hline 2,31 & 0,62 & 0 & 0,082 & 5,88 & $1 / 3 / 2005$ & Atmosfera — Peninsula 1a Fase \\
\hline 2,22 & 0,62 & 0 & 0,069 & 5,76 & $1 / 4 / 2005$ & Atmosfera — Peninsula 2a Fase \\
\hline 2,46 & 0,62 & 0 & 0,069 & 6,04 & $1 / 4 / 2005$ & Residencial Bernini Peninsula \\
\hline 2,21 & 0,62 & 0 & 0,085 & 5,76 & $1 / 8 / 2005$ & Aquarela Peninsula \\
\hline 2,06 & 0,62 & 0 & 0,117 & 5,61 & $10 / 11 / 2005$ & Península Fit \\
\hline 2,00 & 0,83 & 0 & 0,117 & 5,54 & $17 / 11 / 2005$ & Blue Land \\
\hline 2,07 & 0,48 & 1 & 0,117 & 5,70 & $19 / 11 / 2005$ & Pedra de Itaúna (Praia de Itaúna) \\
\hline
\end{tabular}

A partir do estimado logPreço foi apurado um preço médio por metro quadrado de área privativa das unidades lançadas naquele mês de referência. Laferrère (2003) utilizou os registros de preços de cada unidade negociada, no 
mês de referência, calculou um logaritmo do preço para cada um e considerou a média aritmética dos logaritmos, como valor para o índice. Como dispomos apenas das médias dos preços das unidades de cada empreendimento, consideramos a média ponderada pelo número de unidades, para chegar à metodologia adotada.

\begin{tabular}{|lrrrrr|}
\hline \multicolumn{5}{c}{ Ta bela 2} \\
\multicolumn{5}{c}{ Apuração do valor do metro quadrado de área privativa } \\
\hline Unidade & Área privativa & Preço estimado & Lançamento & R $\$ / m^{2}$ & Valor para índice \\
\hline 450 & 88,59 & $265.220,92$ & $1 / 3 / 2002$ & $2.993,81$ & $2.993,81$ \\
120 & 167,73 & $487.786,17$ & $1 / 5 / 2002$ & $2.908,16$ & $2.908,16$ \\
75 & 169,60 & $481.865,40$ & $1 / 6 / 2002$ & $2.841,19$ & $2.841,19$ \\
396 & 65,19 & $181.686,64$ & $1 / 8 / 2002$ & $2.787,03$ & \\
196 & 181,00 & $602.778,48$ & $20 / 8 / 2002$ & $3.330,27$ & $2.966,89$ \\
232 & 134,81 & $386.575,86$ & $26 / 11 / 2002$ & $2.867,51$ & $2.867,51$ \\
360 & 111,29 & $363.473,36$ & $1 / 12 / 2002$ & $3.266,00$ & $3.266,00$ \\
304 & 123,54 & $420.114,04$ & $19 / 6 / 2003$ & $3.400,67$ & $3.400,67$ \\
122 & 158,62 & $459.773,28$ & $1 / 8 / 2003$ & $2.898,55$ & $2.898,55$ \\
320 & 103,25 & $294.282,88$ & $30 / 9 / 2003$ & $2.850,20$ & $2.850,20$ \\
320 & 99,37 & $347.954,50$ & $1 / 11 / 2003$ & $3.501,57$ & \\
47 & 227,32 & $926.118,62$ & $1 / 11 / 2003$ & $4.074,07$ & \\
194 & 125,83 & $397.694,29$ & $1 / 11 / 2003$ & $3.160,63$ & \\
456 & 123,06 & $391.003,57$ & $1 / 11 / 2003$ & $3.177,37$ & $3.317,63$ \\
456 & 123,06 & $395.529,84$ & $1 / 12 / 2003$ & $3.214,16$ & $3.214,16$ \\
356 & 109,84 & $394.268,47$ & $1 / 2 / 2004$ & $3.589,51$ & \\
256 & 72,64 & $239.489,23$ & $17 / 2 / 2004$ & $3.296,93$ & $3.467,13$ \\
272 & 108,25 & $376.977,55$ & $1 / 3 / 2004$ & $3.482,40$ & $3.482,40$ \\
483 & 84,87 & $279.417,03$ & $1 / 5 / 2004$ & $3.292,16$ & $3.292,16$ \\
224 & 102,76 & $339.490,58$ & $1 / 6 / 2004$ & $3.303,68$ & $3.303,68$ \\
58 & 127,44 & $421.897,44$ & $27 / 9 / 2004$ & $3.310,56$ & $3.310,56$ \\
246 & 82,82 & $286.729,35$ & $1 / 11 / 2004$ & $3.462,18$ & $3.462,18$ \\
128 & 177,52 & $740.668,41$ & $1 / 3 / 2005$ & $4.172,31$ & \\
120 & 204,92 & $758.785,89$ & $1 / 3 / 2005$ & $3.702,84$ & $3.945,15$ \\
120 & 167,68 & $580.866,46$ & $1 / 4 / 2005$ & $3.464,14$ & \\
308 & 288,07 & $1.101 .799,10$ & $1 / 4 / 2005$ & $3.824,75$ & $3.723,65$ \\
210 & 162,58 & $581.040,38$ & $1 / 8 / 2005$ & $3.573,88$ & $3.573,88$ \\
264 & 113,83 & $410.262,57$ & $10 / 11 / 2005$ & $3.604,20$ & \\
152 & 99,58 & $346.870,98$ & $17 / 11 / 2005$ & $3.483,36$ & \\
132 & 118,76 & $503.105,21$ & $19 / 11 / 2005$ & $4.236,32$ & $3.722,95$ \\
\hline
\end{tabular}


Embora Tiwari e Hasegawa (2000) recomendem a utilização do índice Fisher (média geométrica, entre os índices com pesos, Laspeyres e Paasche) optamos por um índice simples dada a natureza exploratória da pesquisa.

\begin{tabular}{|c|c|c|}
\hline \multicolumn{3}{|c|}{$\begin{array}{c}\text { Tabela } 3 \\
\text { Apuração do índice (março } 2002=100)\end{array}$} \\
\hline Valor $\mathrm{R} \$ / \mathrm{m}^{2}$ & Mês & Índice \\
\hline $2.993,81$ & mar. 2002 & 100,00 \\
\hline $2.908,16$ & maio 2002 & 97,14 \\
\hline $2.841,19$ & jun. 2002 & 94,90 \\
\hline $2.966,89$ & ago. 2002 & 99,10 \\
\hline $2.867,51$ & nov. 2002 & 95,78 \\
\hline $3.266,00$ & dez. 2002 & 109,09 \\
\hline $3.400,67$ & jun. 2003 & 113,59 \\
\hline $2.898,55$ & ago. 2003 & 96,82 \\
\hline $2.850,20$ & set. 2003 & 95,20 \\
\hline $3.317,63$ & nov. 2003 & 110,82 \\
\hline $3.214,16$ & dez. 2003 & 107,36 \\
\hline $3.467,13$ & fev. 2004 & 115,81 \\
\hline $3.482,40$ & mar. 2004 & 116,32 \\
\hline $3.292,16$ & maio 2004 & 109,97 \\
\hline $3.303,68$ & jun. 2004 & 110,35 \\
\hline $3.310,56$ & set. 2004 & 110,58 \\
\hline $3.462,18$ & nov. 2004 & 115,64 \\
\hline $3.945,15$ & mar. 2005 & 131,78 \\
\hline $3.723,65$ & abr. 2005 & 124,38 \\
\hline $3.573,88$ & ago. 2005 & 119,38 \\
\hline $3.722,95$ & nov. 2005 & 124,35 \\
\hline
\end{tabular}

\section{Conclusão}

O mercado imobiliário no Brasil, voltado para a classe média alta, tem uma característica interessante, isto é, produzir um bem que pode ser vendido para entrega futura, mas com recebimento de parte ou mesmo a totalidade do preço antes de sua entrega. Essa distorção, de levantar recursos para a produção junto aos próprios consumidores, em muito se apóia na crença de que nos lançamentos ocorridos antes do início da construção, os preços são menores, 
de que o investimento imobiliário sempre se valoriza e no paradigma da necessidade da casa própria.

De um lado, a propriedade de um imóvel residencial é vista como um paradigma, um valor tradicional, transmitido de pais para filhos, para que a família seja proprietária de um local digno para sua habitação. Por outro, lado, os lançamentos imobiliários em suas ações de marketing evidenciam os atributos hedônicos dos apartamentos, as facilidades de aquisição e uma promessa implícita de que os preços dos imóveis se valorizarão ao longo do tempo.

Este artigo contraria essa crença, da valorização, ao apresentar evidências de que os preços, na área da Barra da Tijuca, Rio de Janeiro, se desvalorizaram em 2002 (instabilidade política na época das eleições presidenciais) e em 2003 (recessão econômica), somente apresentando alguma recuperação em 2005.

Uma das vantagens de se construir um índice de preços para uma região que se encontra em expansão e dispõe de estoque de terrenos para serem desenvolvidos durante muito tempo é que as unidades já existentes possam ter seus preços estimados por alguma depreciação em relação ao índice de preços dos lançamentos. Esperamos que em futuras pesquisas essa percepção seja confirmada.

Este artigo, embora limitado geograficamente a uma região onde se concentra a atividade de construção residencial e a uma determinada classe social é um ponto de partida.

A proposta de um modelo para a construção de índice de preços de imóveis residenciais, mesmo voltada para um mercado local e para determinado público-alvo, também pode servir de ponto de partida para que as informações sobre as vendas realizadas sejam disponibilizadas por todos os participantes do processo de venda: incorporadores, corretoras, prefeitura (impostos incidentes), tabelionatos e cartórios de registro de imóveis. É função do poder público a regulamentação desses fluxos de informações e sua organização, contribuindo assim com a formação de um banco de dados necessário à formação de um índice nacional de preços de unidades imobiliárias.

Os gerentes das empresas que atuam no mercado imobiliário podem prever melhor seu retorno, aperfeiçoar a produção e detectar oportunidades. Os compradores terão uma ferramenta de análise de preços. Empresas hipotecárias poderão avaliar seus riscos e se proteger contra grandes oscilações e, por fim, o mercado financeiro poderá lançar produtos de proteção contra um dos menos observados problemas do patrimônio imobiliário, a perda de valor. 


\section{Referências bibliográficas}

ALENCAR, Claudio T.; LAZZAROTTO, Carlos A. F. Construção de um índice de preços do mercado residencial: um estudo na cidade de São Paulo. Produção em Iniciação Científica da Escola Politécnica da USP, v. 1, São Paulo, 2002.

BENSON, Earl D. et al. Pricing residential amenities: the value of a view. Journal of Real Estate Finance and Economics, v. 16, n. 1, p. 55-73, 1998.

BOND, Michael T.; SEILER, Vicky L.; SEILER, Michael J. Residential real estate prices: a room with a view. Journal of Real Estate Research, v. 23, n. 1-2, p. 129-138, 2002.

BOURASSA, Steven C.; HOESLI, Martin; SUN, Jian. A simple alternative house price index method. International Center for Financial Asset Management and Engineering. (Fame Research Paper Series, n. 119). Disponível em: <www.borg.hi.is/enhr2005iceland/ppr/ Bourassa-Hoesli-Sun.pdf $>$. Acesso em: 20 jul. 2006.

BUCK, Andrew J.; HAKIM, Simon; SPIEGEL, Uriel. Endogenous crime victimization, taxes and property values. Social Science Quarterly, v. 74, n. 2, p. 334-348, 1993.

CALHOUN, C. A. Ofheo house price indexes: HPI technical description, 1996. Disponível em: <www.ofheo.gov/Media/Archive/house/hpi_tech.pdf>. Acesso em: 28 jul. 2006.

CARNEIRO, Dionísio D.; VALPASSOS, Marcus V. F. Financiamento à habitação e instabilidade econômica. Rio de Janeiro: FGV, 2003.

CASE, Karl E.; SHILLER, Robert J. The efficiency of the market for single-family homes. The American Economic Review, v. 79, n. 1, p. 125-137, 1989.

CASE, Bradford; QUIGLEY, John M. The dynamics of real estate prices. The Review of Economics and Statistics, v. 73, n. 1, p. 50-58, 1991.

; SZYMANOSKI, E. J. Precision in house price indices: findings of a comparative study of house price index. Journal of Housing Research, v. 6, n. 3, p. 483-496, 1995.

CAULEY, Stephen D.; PAVLOV, Andrey D. Rational delays: the case of real estate. Journal of Real Estate Finance and Economics, v. 24, 2002. 
CHAU, K. W. et al. Real estate price indices in Hong Kong. Journal of Real Estate Literature, v. 13, n. 3, p. 337-356, 2005.

CLAPP, John M. A semi parametric method for estimating local house price indices. Real Estate Economics, v. 32, p. 127-160, 2004.

; GIACCOTTO, Carmelo. Price indices based on the hedonic repeat-sales method: application to the housing market. The Journal of Real Estate Finance and Economics, v. 16, n. 1, p. 5-26, 1998.

; n. 1, p. 1-26, 2002.

. Evaluating house price forecasts. Journal of Real Estate Research, v. 24,

CONNIFFE, Denis; DUFFY, David. Irish house price indices - methodological issues. The Economic and Social Review, v. 30, n. 4, p. 403-423, 1999.

DIN, Allan; HOESLI Martin; BENDER, André. Environmental variables and real estate prices. Urban Studies, v. 38, n. 11, p. 1984-2000, 2001.

ENGLUND, Peter; QUIGLEY, John M.; REDFEARN, Christian. The choice of methodology for computing housing price indexes: comparisons of temporal aggregation and sample definition. Journal of Real Estate Finance and Economics, v. 19, n. 2, p. 91-112, 1999.

FREW, James; JUD, Donald G. Estimating the value of apartment buildings. Journal of Real Estate Research, v. 25, n. 1, p. 77-86, 2003.

GIROUARD, Nathalie et al. Recent house price developments: the role of fundamentals. (Economics Department Working Papers n. 475.) Disponível em: <www.olis.oecd.org/olis /2006doc.nsf/linkto/ECO-WKP(2006)3>. Acesso em: 15 jul. 2006.

GONÇALVES, Robson R. O déficit habitacional brasileiro: um mapeamento por unidades da federação e por níveis de renda familiar. Ipea, 1998. (Texto para discussão n. 559). Disponível em: <www.ipea.gov.br/pub/td/td0559.pdf>. Acesso em: 29 jul. 2006.

GOODMAN, Allen C.; THIBODEAU, Thomas G. Age related heteroskedasticity in hedonic house price equations. Journal of Housing Research, v. 6, n. 1, p. 25-42, 1995.

Dwelling-age related heteroskedasticity in hedonic house price equations: an extension. Journal of Housing Research, v. 8, n. 2, p. 299-318, 1997. 
GUIRGUIS, Hany S.; GIANNIKOS, Christos I.; ANDERSON, Randy I. The US housing market: asset pricing forecasts using time varying coefficients. The Journal of Real Estate Finance and Economics, v. 30, p. 33-53, 2005.

HOAG, James, W. Towards. Indices of real estate value and return. The Journal of Finance, v. 35, n. 2, p. 569-580, 1980.

HWANG, Min; QUIGLEY, John M. Selectivity, quality adjustment and mean reversion in the measurement of house values. Journal of Real Estate Finance and Economics, v. 28, p. 161-178, 2004.

ISAKSON, Hans R. Using multiple regression analysis in real estate appraisal. The Appraisal Journal, n. 64, p. 11-24, 2001.

JUD, Donald G.; WINKLER, Daniel T. The dynamics of metropolitan housing prices. Journal of Real Estate Research, v. 23, n. 1-2, 2002.

KNIGHT, J. R.; DOMBROW, J.; SIRMANS, C. F. A varying parameters approach to constructing house price indexes. Real Estate Economics, v. 23, n. 2, p. 187-205, 1995.

LAFERRÈRE, Anne. Hedonic housing prices index: the French experience. BIS Papers, n. 21, 2003. Disponível em: <www.bis.org/publ/bppdf/bispap21v.pdf>. Acesso em: 20 jul. 2006.

LEISHMAN, Chris; WATKINS, Craig. Estimating local repeat sales house price indices for British cities. Journal of Property Investment \& Finance, v. 20, n. 1, p. 36-58, 2002.

MACANHAN, Vanessa B. P.; MONTEVECHI, José A. B.; PAMPLONA, Edson O. Análise sobre a rentabilidade no mercado de imóveis - uma aplicação em uma região da cidade do Rio de Janeiro. In: ENCONTRO NACIONAL DE ENGENHARIA DE PRODUÇÃO. 21. Anais... Salvador, Bahia, 2001.

MAIA, Rosemere S. A. Produção do espaço em áreas de auto segregação: o caso da Barra da Tijuca. Anuário do Instituto de Geociências - UFRJ, v. 21, p. 39-75, 1998.

MALPEZZI, Stephen. Hedonic pricing models: a selective and applied review. In: GIBB, K.; O'SUlLIVAN, A. (Eds.). Housing economics: essays in honor of Duncan Maclennan. 2002. Disponível em:<www.bus.wisc.edu/wcre/paper.asp>. Acesso em: 25 jul. 2006. 
MARK, Jonathan H.; GOLDBERG, Michael A. Alternative housing price indices: an evaluation. Areuea Journal, v. 12, n. 1, p. 30-49, 1984.

MEESE, Richard A.; WALLACE, Nancy. E. The construction of residential housing prices indices: a comparison of repeat-sales, hedonic regression and hybrid approaches. Journal of Real Estate and Economics, n. 14, p. 51-73, 1997.

PALMQUIST, Raymond B. Alternative techniques for developing real estate prices indexes. The Review of Economics and Statistics, v. 62, n. 3, p. 442-448, 1980.

SCHWANN, Gregory M. A real estate price index for thin markets. Journal of Real Estate Finance and Economics, v. 16, n. 3, p. 269-287, 1998.

SHILLER, Robert J. Arithmetic repeat sales price estimators. Journal of Housing Economics, n. 1, p. 110-126, 1991.

SIRMANS, Stacy, G.; MACPHERSON, David, A.; ZIETZ, Emily, N. The composition of hedonic pricing models. Journal of Real Estate Literature, v. 13, n. 1, p. 3-43, 2005.

SMITH, Brent C. Economic depreciation of residential real estate: microlevel space and time analysis. Real Estate Economics, v. 32, p. 161-180, 2004.

STEPHENS, W. et al. Conventional mortgage home price index. Journal of Housing Research, v. 6, n. 3, 1995.

TIWARI, Piyush; HASEGAWA, Hiroshi. House price dynamics in Mumbai, 1989-1995. Rurds, v. 12, n. 2, p. 149-163, 2000.

WANG, Ferdinand T.; ZORN, Peter M. Estimating house price growth with repeat sales data: what's the aim of the game? Journal of Housing Economics, v. 6, p. 93-118, 1997.

WUBNEH, Mulatu; SHEN, Guoqiang. The impact of manufactured housing on adjacent residential property values: a gis approach based on three North Carolina Counties. Rurds, v. 6 , n. 1, p. 56-73, 2004.

YOUNG, Michael S.; GRAFF, Richard A. Real estate is not normal: a fresh look at real estate return distributions. Journal of Real Estate Finance and Economics, v. 10, n. 3, p. 225-259, 1995. 


\section{Anexo}

Distribuição geográfica dos empreendimentos na Barra da Tijuca, Rio de Janeiro, $\mathrm{RJ}$

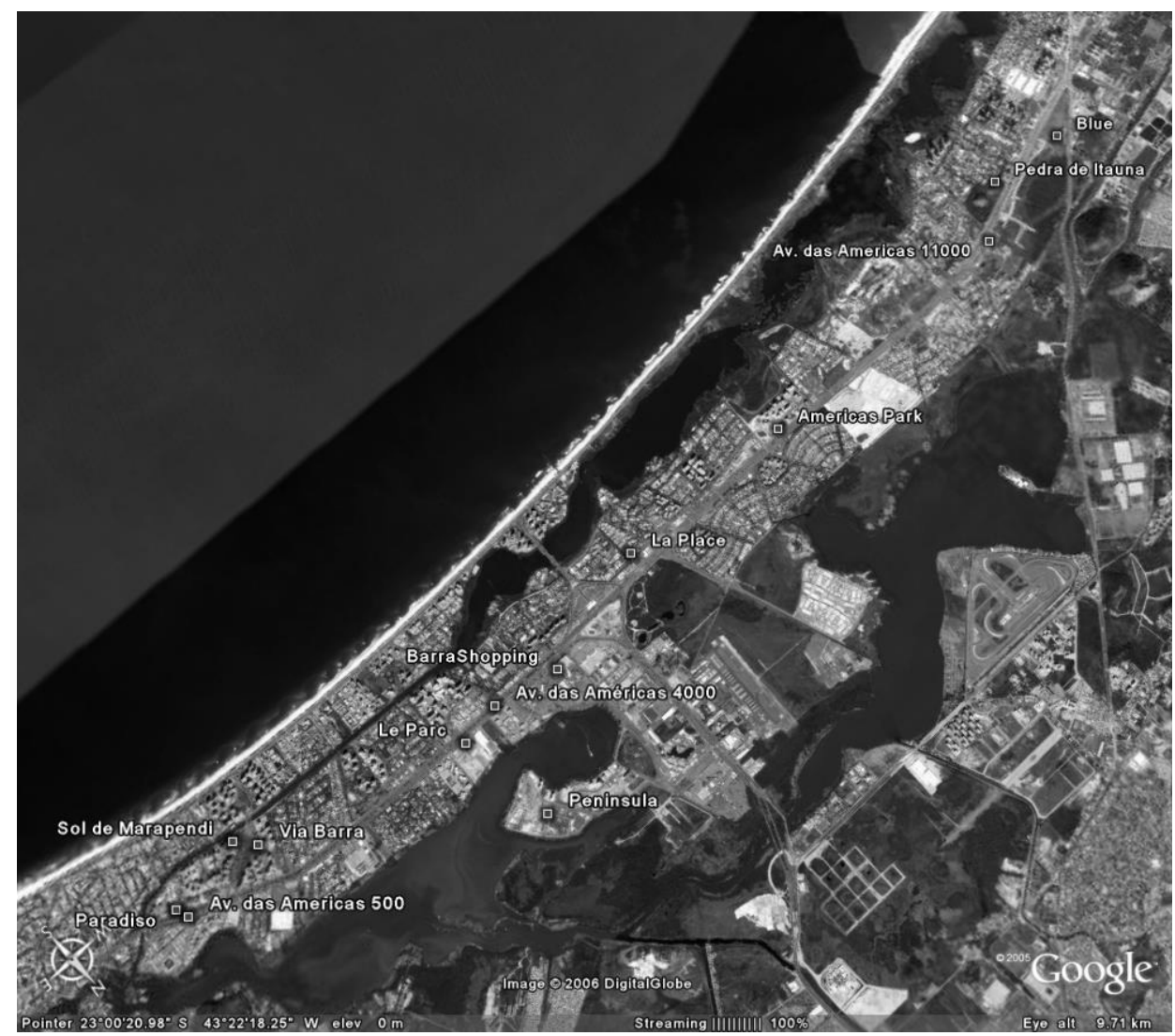

A região da avenida das Américas, eixo principal da Barra da Tijuca, tem aproximadamente $10 \mathrm{~km}$ de extensão (dentro da Barra da Tijuca) por $1 \mathrm{~km}$ de largura. Comparada a Miami Beach pelos incorporadores, guarda alguma semelhança, pela faixa de terra entre o mar e as lagoas. Problemas de infraestrutura de saneamento, transportes e segurança não impedem o crescimento acelerado do mercado imobiliário para a classe média alta. 